Revista NEP, Núcleo de Estudos Paranaenses, Curitiba, v.4, n.2, dez. 2018

\title{
Política: o canal da televisão paranaense
}

Bruno Bonet Strack Reis de Andrade ${ }^{1}$

\begin{abstract}
Resumo: Este artigo tem como objetivo fazer um resgate histórico das primeiras concessões de televisão no Paraná, fazendo uma breve análise do perfil dos dirigentes das emissores e suas relações com o poder, bem como do processo de obtenção das concessões.
\end{abstract}

Palavras-chave: Televisão. Empresas de Comunicação. Poder.

\section{Politics: the paranaense television channel}

\begin{abstract}
This article aims to make a historical rescue of the first television concessions in Paraná, making a brief analysis of the profile of the managers of the issuers and their relations with power, as well as the process of obtaining the concessions.
\end{abstract}

Keywords: Television. Communication companies. Power.

\section{Introdução}

Atualmente poucas famílias controlam os meios de comunicação no Paraná, em 1960 não era diferente e esse grupo era ainda mais seleto.

Nosso estudo trata das três primeiras emissoras de televisão do Paraná, a TV Paranaense fundada pelo empresário Nagib Chede, a TV Paraná de propriedade do magnata das telecomunicações e político Assis Chateaubriand e a TV Iguaçú, fundada pelo ex-governador Paulo Pimentel. O objetivo do estudo é fazer um breve resgate das peculiaridades para obtenção das concessões das emissoras mostrando ser um processo muito mais politico do que técnico.

\section{Antecedentes}

\footnotetext{
1 Aluno do Curso de Engenharia Elétrica da Universidade Tecnológica Federal do Paraná, UTFPR.
} 
Revista NEP, Núcleo de Estudos Paranaenses, Curitiba, v.4, n.2, dez. 2018

Em 1953, diversos empresários e políticos paranaenses firmaram sociedade e registram a Rádio e Televisão do Paraná S.A. A primeira transmissão pública só acontece um ano depois, em 17 de junho de $1954^{1}$ nas vitrines da loja Tarobá onde foram colocados dois receptores, houve uma multidão de curiosos e a programação veio de um estúdio improvisado em uma kitnet no mesmo prédio. Apesar do sucesso dessa primeira exibição, a televisão no Paraná só começa oficialmente em 1960 numa Curitiba com uma população de 361.309 habitantes segundo o censo da época, havia uma crescente demanda até a chegada da televisão com a TV Paranaense (CARVALHO, 2004).

\section{TV Paranaense (CANAL 12)}

Inaugurada em 29 de outubro de 1960 pelo empresário Nagibe Chede Abrahão, nascido em Palmeira, em 28 de maio de 1911, filho de Chede Abrahão e Rosa Abrahão, irmão mais novo de João Chede Abrahão, que foi prefeito de Palmeira e deputado estadual eleito nas legislaturas de 1947 e 1950. Joâo Chede era amigo pessoal e afilhado político de Manoel Ribas e apoiou a campanha de Moises Lupion para o governo estadual (GOULART, 2017). Em 1930 ingressou na Universidade Federal do Paraná, na qual concluiu em 1935 o curso de Direito, sendo um dos primeiros advogados inscritos na OAB. Casou-se 1934 com Sylmira Takues Chede, com quem teve uma única filha, Marisa $^{2}$.

Nagib já era proprietário de duas emissoras de rádio e era amigo de longa data de Moises Lupion, membro do mesmo grupo Político de Manoel Ribas, Lupion no primeiro mandato como governador (1947-1951) nomeou Nagib para o Tribunal de Contas (GOULART, 2017), e no segundo mandato a frente do Palácio Iguaçú (1956-1961) foi uma pessoa fundamental para a concessão do Canal 12, que desde 1957 estava com a solicitação parada na Comissão Técnica de Rádio, Lupion interveio agendando audiência com Juscelino Kubitschek, presidente na época, que insistiu que Lupion retomasse o Iguaçú em 1955 (MILLARCH, 1990).

As negociações comuns daquele período aconteciam entre os empresários e a direção da CTR; ou no máximo eram intermediadas no Gabinete da Presidência da República por deputados federais e senadores da base aliada. Isto ocorria porque a expansão do sistema de televisão pelo país fazia parte da estratégia do governo JK. O crescimento inicial da televisão, a partir de 1950, deveu-se ao favoritismo político, o qual concedia licenças para exploração de canais sem um planejamento preestabelecido. Assim, a proliferação de estações de televisão começou 


\title{
Revista NEP, Núcleo de Estudos Paranaenses, Curitiba, v.4, n.2, dez. 2018
}

durante a administração do presidente Juscelino Kubitschek, de 1956 a 1961 (MATTOS, 2002: 51).

Mostrando que desde a gênese da televisão no Paraná havia a necessidade de forte capital político junto aos Palácios do Iguaçú e do Planalto, bem como uma relação pessoal para se obter a concessão de uma emissora de televisão, mais que uma concessão, um presente de amigo.

\begin{abstract}
Na audiência no Palácio do Catete, em 24 de novembro de 1959, o empresário fez uma exposição do problema para o presidente da República, o qual após ouvi-la teria dito: "Sem problema nenhum, você vai dar ao povo de Curitiba uma estação de televisão; eu vou lhe dar um canal." Ato contínuo, JK chamou o seu oficial de Gabinete e entregou-lhe uma autorização dizendo: "Você me entregue isso com a máxima brevidade ao ministro de Obras Públicas". O titular da pasta era Amaral Peixoto, o qual, conforme Chede era seu amigo de longa data em decorrência de militância getulista em tempos anteriores. Tendo recebido a autorização assinada pelo presidente Juscelino Kubitschek, o ministro entregou a Chede um ofício dirigido à Comissão Técnica de Rádio, designando um canal de televisão para a Sociedade Rádio Emissora Paranaense, que seria o Canal 12 de Curitiba... A autorização do presidente Juscelino Kubitschek, encaminhada ao ministro de Viação e Obras Públicas Amaral Peixoto, para os trâmites da concessão da emissora de TV a Chede foi assinada, naquela audiência de novembro de 1959, no próprio ofício de solicitação entregue por Lupion, em papel com a logomarca do Gabinete do Governador do Estado do Paraná (COSTA, 2013).
\end{abstract}

A TV Paranaense ficou nas mãos de Nagib Chede até ser vendida em 1969 para Francisco Cunha Pereira Filho, nascido em Curitiba, em 7 de dezembro de 1926. Filho de Francisco Cunha Pereira e Júlia do Amaral Ferreira. Por influência do pai, Cunha prestou vestibular para Direito na Universidade Federal do Paraná onde formou-se em 1949. Até 1962, Cunha Pereira teve uma bemsucedida carreira como criminalista, que trocou pelo jornalismo quando comprou a Gazeta do Povo, em sociedade com Edmundo Lemanski. Sociedade firmada novamente na compra TV Paranaense, firmando-se como empresário do campo das comunicações (MARCELINO, 2016).

A família Cunha Pereira remonta a troncos vindos de Minas Gerais, com Senadores, Procuradores e altos membros do judiciário na parentela. O pai de Francisco Cunha Pereira foi juiz, desembargador, fundador e diretor da Faculdade de Direito de Curitiba e conselheiro do Bamerindus. Sua mãe era filha de João Cândido Ferreira, médico, deputado estadual e federal e vice-presidente do estado no governo Vicente Machado, e sobrinha de Victor Ferreira do Amaral, médico patrono da Universidade Federal do Paraná e também deputado estadual (MARCELINO, 2016). 
Revista NEP, Núcleo de Estudos Paranaenses, Curitiba, v.4, n.2, dez. 2018

Atualmente o grupo GRPCOM é presidido por Guilherme Döring Cunha Pereira, um dos filhos de Francisco Cunha Pereira Filho. Guilherme é doutor em direito pela USP e também comanda além do GRPCOM outras 16 empresas da família (MARCELINO, 2016).

\section{TV Paraná (CANAL 6)}

Inaugurada em 19 de dezembro de 1960, de posse dos Diários Associados, controlados pelo politico e empresario Francisco Assis Chateaubriand Bandeira de Melo ${ }^{7}$, nascido em Umbuzeiro (PB) no dia 5 de outubro de 1892, filho de Francisco Chateaubriand Bandeira de Melo e de Carmem Gondim Bandeira de Melo. Seu pai, bacharel em direito, foi funcionário da alfândega. Embora pouco abastado, pertencia a tradicional família de senhores de engenho, que remontava ao período da dominação holandesa. Ingressou na Faculdade de Direito de Recife em 1908 onde formou-se em 1913. Foi editor-chefe de diversos jornais, até que em 1924 compra seu primeiro jornal no Rio de Janeiro e começa o que viria a ser o maior conglomerado de mídia da América Latina, os Diários Associados. O investimento televisivo do grupo inicia nos anos 1950, tendo como foco o eixo RioSão Paulo, apenas em 1960 obtém a concessão de uma emissora para atuar no Paraná, Osmani Costa destaca que o processo de obtenção das licenças foi relativamente simples pois Chateaubriand gozava de muita influencia com Kubitscheck, visto que também era embaixador do Brasil na Inglaterra e a televisão estava dentre os interesses nacionais. Em 1961 obteve uma segunda concessão de televisão, já no governo Jânio Quadros (COSTA, 2013).

Chateaubriand faleceu em 1968 e os Diários Associados entrou em processo falimentar, a TV Paraná foi vendida em 1974 ao grupo OM, de propriedade do empresário Oscar Martinez, presidida por seu filho o empresário e politico José Carlos de Castro Martinez, nascido em São Paulo em 23 de maio de 1948, filho de Oscar Martinez e de Joanice de Castro Martinez. Cursou até o segundo ano de direito e o quarto ano de administração, abandonando os cursos para trabalhar nas empresas da família. Foi deputado federal pelo Paraná nas legendas de 1983, 1987 e 1999, envolveu-se em diversos escândalos do "esquema PC" durante o governo Collor.

Em 1992 a TV Paraná - Canal 6 passou a ser chamada de a Cadeia OM de Comunicação. Assim, José Carlos Martinez criou a primeira rede nacional fora do eixo Rio - São Paulo. Atualmente a Cadeia OM denomina-se, após parceria com TV Gazeta de São Paulo, CNT 
Revista NEP, Núcleo de Estudos Paranaenses, Curitiba, v.4, n.2, dez. 2018

- Central Nacional de Televisão. Sua programação, por ser uma Rede Paranaense, apresenta maior conteúdo regional (PRESAS, 2003).

\title{
5. TV Iguaçú (CANAL 4)
}

De propriedade do politico e empresário Paulo Cruz Pimentel ${ }^{\mathbf{1 0}}$, nascido em Avaré em 7 de agosto de 1928, filho de Públio Pimentel e de Maria Isabel Cruz Pimentel.

\begin{abstract}
Formou-se em direito no ano de 1952 pela Universidade de São Paulo. No mesmo ano de sua formatura, passou a trabalhar como consultor jurídico, e depois diretor financeiro, na firma Ricardo Lunardelli, da família de sua noiva, Yvone Lunardelli. Em 1955, já casado, transferiu-se para o Paraná como diretor da Usina dos Lunardelli... Em 1960, participou da campanha eleitoral de Ney Braga, para o governo do Paraná, cobrindo juntamente com seu sogro, João Lunardelli, o norte do estado. Com a vitória de Ney Braga e sua posse em 31 de janeiro do ano seguinte, foi convidado a assumir a Secretaria de Agricultura do estado... Deixando a Secretaria de Agricultura do Paraná em 1965, lançou sua candidatura ao governo do estado. Sua candidatura foi também formalmente endossada, por Ney Braga. Sua campanha foi em grande parte financiada pelo empresário Jaime Cannet Júnior. ${ }^{10}$
\end{abstract}

A obtenção de três concessões de emissoras por Pimentel em 1967 vem de uma conjuntura favorável, após a tomada de poder pelos militares houve um maciço desenvolvimento em tecnologias, porém a regulamentação foi ainda mais estreitada pelo governo federal, fazendo-se necessário ainda mais prestígio político do que sete anos antes no caso do Canal 12. Pimentel desde 1962 quando ainda comandava a pasta da agricultora no governo Ney Braga, ainda no governo de João Goulart solicitava a licença. Dois meses após o início do novo regime foi lançado edital para concessão de uma terceira emissora de televisão e Pimentel já era tido como favorito na disputa.

Indícios de que Paulo Pimentel era o preferido, no Palácio do Planalto, para receber a concessão do terceiro canal de TV de Curitiba, já tinham sido percebidos pela imprensa local nos últimos meses de 1964. No início de setembro daquele ano, Castelo Branco havia visitado Curitiba pela primeira vez, depois da posse dele na Presidência da República. Na oportunidade, o presidente concedeu demorada audiência a portas fechadas para Ney Braga e Pimentel. Castelo Branco era amigo íntimo do governador do Paraná havia décadas, desde a época em que fora professor-instrutor de Ney Braga na Escola Militar do Realengo, no Rio de Janeiro...(COSTA, 2013).

O próprio Pimentel em entrevista destacou a importância da relação com o Planalto e como o processo de licitação era politicamente manipulável. 
Revista NEP, Núcleo de Estudos Paranaenses, Curitiba, v.4, n.2, dez. 2018

\begin{abstract}
Havia uma licitação pública, sim. Havia a coleta de pretendentes ao canal. Depois, aqueles [empresários candidatos] que se habilitavam [no Conselho Nacional de Telecomunicações] iam para a decisão do presidente [daRepública]. A decisão era exclusiva dele. Era política. Então, todos nós trabalhávamos politicamente. Cada concorrente achava o pistolão que precisava pra conseguir. E quem tivesse mais força política ganharia. O presidente era o Castelo Branco, quando saiu a concorrência do Canal 4. Eu fui chamado [em Brasília] para saber se eu não queria montar esta estação de televisão [a Iguaçu]. Até que eu não tinha muito interesse, porque não tinha programação, não tinha coisa alguma além dos dois jornais. Mas a decisão era do presidente da República e ele escolhia os beneficiários, os que seriam premiados com esta estação. Fui convidado, e o presidente Castelo Branco me deu [a concessão do Canal 4]. (PIMENTEL, 2009)
\end{abstract}

Já empossado governador, em 1967, Pimentel foi o único governador na posse de Costa e Silva, o que lhe foi prontamente recompensado com uma segunda concessão, o Canal 11 em Apucarana, a TV Tibagi, no dia seguinte a inauguração da TV Iguaçú, que foi inaugurada em 28 de dezembro de 1967.

Passados mais de dez anos da inauguração da TV Tibagi - e após uma grave crise política que não é aqui analisada por falta de espaço -, Paulo Pimentel reaproximou-se de Ney Braga e do poder central, no início da década de 1980. O general João Batista de Oliveira Figueiredo era o presidente da República (1979-1985) e o general-reformado Ney Braga (ARENA) ocupava pela segunda vez o Palácio Iguaçu, para o mandato 1979-1982. Contando com o respaldo dos dois líderes, Pimentel conseguiu a sua terceira e última concessão de emissora durante o regime militar, a TV Naipi, que inauguraria em Foz do Iguaçu em setembro de 1985.

Quase duas décadas depois de ter recebido sua primeira concessão de TV, Paulo Pimentel conseguia assim a sua terceira outorga de canal. Com a conquista da concessão do Canal 12 de Foz do Iguaçu, encerrou-se a fase de negociações de Paulo Pimentel com o governo militar, que também estava terminando o seu ciclo de 21 anos de comando sobre a nação (COSTA, 2013).

Pimentel participou da constituinte de 1988 e encerrou o mandato de deputado Federal em 1991, durante a década de 1990 dedicou-se às empresas do Grupo Paulo Pimentel. Em 2002 aproxima-se de Roberto Requião e com o uso de seu aparelho de mídia ajuda na eleição de Requião para o governo do Estado. Após ser empossado como governador Requião, nomeia Pimentel presidente da COPEL, cargo que ocupou até 2005.

Em setembro de 2007, o apresentador e empresário Carlos Massa, Ratinho comprou as emissoras e retransmissoras do GPP por cerca de 70 milhões de reais ${ }^{12}$. Massa é pai do deputado estadual Ratinho Júnior, que é secretário de estado do governador Beto Richa. 
Revista NEP, Núcleo de Estudos Paranaenses, Curitiba, v.4, n.2, dez. 2018

A família Massa continua comandando o Canal 4, Rede Massa.

\section{Referências}

BARACHO, Maria Luiza Gonçalves; MODERNIDADE EM PRETO E BRANCO: a televisão em Curitiba; 2007 Disponível em: <.http://www.poshistoria.ufpr.br/documentos/2007/Maria\%20Luiza\%20G.\%20Baracho.pdf.>. Acesso em: 15/11/2017.

Confirmado: Ratinho compra SBT. Disponível em: <http://www.bemparana.com.br/politicaemdebate/index.php/2007/09/01/confirmado-ratinhocompra-sbt/>. Acesso em: 16/11/2017.

CARVALHO, Joyce. Primeira transmissão de TV faz 54 anos , Tribuna do Paraná, 2004 Disponível em: <http://www.tribunapr.com.br/noticias/parana/primeira-transmissao-de-tv-faz-54anos/>. Acesso em: 15/11/2017.

COSTA, Osmani Ferreira Televisão no Paraná: uma história política da implantação dos primeiros canais (1960-1985). Disponível em: <http://www.snh2013.anpuh.org/resources/anais/27/1364438756_ARQUIVO_ArtigoparaANPUH2 013.pdf $>$. Acesso em: 15/11/2017.

COSTA, Osmani Ferreira da. Televisão e Política: Uma história da televisão no Paraná (19541985). Londrina: Editora UEL, 2015.

DALLA COSTA, Rosa Maria Cardoso; A História da Televisão no Paraná: um jeito próprio de fazer parte da televisão brasileira; II Encontro Nacional da Rede Alfredo de CarvalhoFlorianópolis, abril de 2004. Disponível em: <https://www.ufrgs.br\%2Falcar\%2Fencontros-nacionais-1\%2Fencontrosnacionais\%2F2o-encontro-2004-

1\%2FA\%2520Historia\%2520da\%2520Televisao\%2520no\%2520Parana\%2520um\%2520jeito\%252 0proprio\%2520de\%2520fazer\%2520parte\%2520da\%2520televisao\%2520brasileira.doc\&usg=AOv Vaw2qrdGM17saDcb7TXSu71Tx >. Acesso em: 15/11/2017.

FGV CPDOC: MOISES LUPION DE TROYA, Disponível em: < http://www.fgv.br/cpdoc/acervo/dicionarios/verbete-biografico/moises-lupion-de-troya $>$. Acesso em: $15 / 11 / 2017$.

FRANCISCO DE ASSIS CHATEAUBRIAND BANDEIRA DE MELO CPDOC Disponível em: <http://www.fgv.br/cpdoc/acervo/dicionarios/verbete-biografico/francisco-de-assis-chateaubriandbandeira-de-melo> . Acesso em: 15/11/2017.

GOULART, Mônica Helena Harrich Silva. Os detentores da caneta: apontamentos sobre os presidentes da Assembleia Legislativa do Paraná (1935-1962). In: OLIVEIRA, Ricardo C. de; VANALI, Ana C. Instituições e Poder Político. 1. ed. Curitiba: Prismas, 2017, p. 17-92. 
GRPCOM: CONSELHO DE ADMINISTRAÇÃO. Disponível em: http://www.grpcom.com.br/grpcom/conselho-de-administracao.html. Acesso em 15.nov.2017

JOSÉ CARLOS DE CASTRO MARTINEZ. CPDOC Disponível em: http://www.fgv.br/cpdoc/acervo/dicionarios/verbete-biografico/jose-carlos-de-castro-martinez. Acesso em 15.nov.2017

NAGIBE Chede Abrahão (1993 - Memória Viva) Direito - Palmeira - Paraná. Disponível em: <http://memoriasparana.com.br/nagib-chede-1993/>. Acesso em: 15/11/2017.

NICOLAS, Maria. 130 anos de vida Parlamentar, 1954. Disponível em: <http://www.alep.pr.gov.br/deputados/perfil/86-joao-chede $>$. Acesso em: 15/11/2017.

PAULO CRUZ PIMENTEL - CPDOC. Disponível em: http://www.fgv.br/cpdoc/acervo/dicionarios/verbete-biografico/paulo-cruz-pimentel. Acesso em 16.nov.2017

PEREIRA, Fernando Marcelino Breve genealogia da família Cunha Pereira. Revista NEP, n.2.v.2, Disponível em: <http://revistas.ufpr.br/nep/article/view/46984/28177>. Acesso em: 14/11/2017.

PRESAS, Guadalupe Fernandes. A desregionalização da televisão: uma análise do fenômeno no Paraná, 2003, p.24. 2 Disponível em: <http://www.historia.ufpr.br/monografias/2002/guadalupe_fernandez_presas.pdf >. Acesso em: $16 / 11 / 2017$.

Recebido: 13 nov. 2018

Aceito: 04 dez. 2018 